\title{
Deficiencia de hierro, la injusta herencia
}

\section{Iron deficiency, an unfair inheritance}

Hace unos 20 años George R. Buchanan, Prof. del Departamento de Pediatría de la Universidad de Texas titulaba una editorial en Journal of Pediatrics "La tragedia de la deficiencia de hierro en lactantes y primera infancia". ${ }^{1}$

En su escrito llamaba la atención que la anemia nutricional por deficiencia de hierro, continuaba siendo un problema prevalente; lo planteaba, citando a colegas de su país, como un "fracaso pediátrico", a la vez con decepción y tristeza por tratarse de un problema prevenible. Él mismo planteaba que quizás la palabra tragedia podía sonar fuerte frente a otras enfermedades como el cáncer o graves anomalías congénitas. La deficiencia de hierro es raramente fatal; sin embargo es una tragedia, por sus efectos sobre el cerebro debido a las lesiones irreversibles causadas por prácticas nutricionales inadecuadas. ${ }^{1}$

En nuestro país la anemia nutricional por deficiencia de hierro continúa siendo un problema prevalente en niños menores de dos años. Otros grupos etarios vulnerables como menores de 6 años, embarazadas y madres en periodo de lactancia están alcanzados por cifras indeseables de la prevalencia de anemia., ${ }^{2,3}$ En algunas regiones predominan las anemias nutricionales leves o moderadas, sobre las que no sabemos el impacto que podrían tener sobre el desarrollo de nuestros niños, en otros casos la anemia puede ser más grave.

El trabajo de Zapata et al., publicado en este número de Archivos es importante. Es necesario conocer la información que ofrecen los autores para profundizar en las medidas preventivas para la salud pública y la atención clínica. Conocer las fuentes alimentarias de hierro y folato es un aporte para la toma de decisión en las estrategias de abordaje de un problema que pareciera simple, pero que el tiempo demuestra que no podemos resolver. ${ }^{4}$

La elaboración del trabajo desde el CESNI (Centro de Estudio sobre Nutrición Infantil), retoma una historia de compromiso de la institución con el tema. En el año 1992 la Dra. Elvira Calvo et al., en un estudio colaborativo entre la Maternidad Sardá y el CESNI publicaban sus resultados de la prevalencia de anemia y deficiencia de hierro en lactantes a los 9 meses de edad que alcanzaba al $27 \%$ de los niños que habían sido amamantados exclusivamente hasta los 6 meses, y propusieron la recomendación de suplemento de Fe desde los 4 meses de edad. ${ }^{5}$

También la Dra. Calvo desde CESNI en 1990 comunicó los resultados de la alta prevalencia de anemia $(46,7 \%)$ en niños de 9 a 24 meses, de los cuales el $46 \%$ presentaba al menos 2 de 3 indicadores bioquímicos de deficiencia de hierro. Los resultados fueron asociados a la introducción temprana de leche de vaca entera, bajo consumo de alimentos fortificados y la no suplementación con hierro. ${ }^{6}$

Posteriormente el Dr. Alejandro O`Donnell (quien fuera el Director de CESNI) junto a sus colaboradores en el año 1997, hace una revisión interesante en el que resume los resultados de la mayoría de los principales estudios sobre la deficiencia de hierro y la anemia en lactantes, preescolares, mujeres en edad fértil y embarazadas en la Argentina. Asimismo, expresaron su preocupación por la no resolución de un problema que llevaba por entonces varios años, y se expusieron razones similares que los estudios anteriores para las altas prevalencias de deficiencia de hierro y anemia en diferentes grupos poblacionales. ${ }^{7}$

Esos resultados en embarazadas y menores de dos años se repitieron o mostraron prevalencias aún mayores en estudios posteriores, en el año 2002 y 2003, realizados en Chaco por la Dra. María del Carmen Moraso et al., y también en la Provincia de Bs As en la evaluación de impacto de un programa alimentario en 2003-2004 comunicados por Varea et al. y Malpeli et al.,8-11

Años más tarde, la Encuesta Nacional de Nutrición y Salud realizada en 2005, un hito en la evaluación nutricional de nuestra población, mostró prevalencias altas de anemia en todo el país en diferentes grupos etarios. ${ }^{2}$ Las cifras fueron preocupantes, no se mostraban cambios importantes respecto de estudios regionales previos.

En la Argentina, el enriquecimiento de la harina de trigo fue establecido por Ley $\mathrm{N}^{\circ} 25.630$, sancionada en julio de 2002. La reglamentación (Decreto No 597/03), fue publicada en el Boletín Oficial el 14 de agosto de 2003. También fue un hito en la lucha por la superación de la deficiencia de hierro y folato. La Dra. Calvo mostró que la fortificación de la harina con ácido fólico se asociaba con ingestas y niveles séricos adecuados 
de folatos en las mujeres. Observó de manera concurrente una reducción significativa en la prevalencia de los defectos del tubo neural y la mortalidad por esa causa. ${ }^{12}$

Sin embargo, los resultados sobre deficiencia de hierro no acompañaron de la misma forma. El preocupante diagnóstico hecho por Bernztein y Drake en 2008 acerca de la subprescripción de hierro en el primer nivel de atención fue una importante contribución para explicar al menos parcialmente el fenómeno de la persistencia del problema y no tenemos información fehaciente que haya mejorado. ${ }^{13}$

Por otro lado, sabemos la importancia de la ligadura oportuna de cordón, incluso con estudios hechos en nuestro medio por el Dr. Ceriani Cernadas et al., en los que se demuestra que el clampeo de cordón a los 3 minutos aumenta significativamente la ferritina a los 6 meses de edad. ${ }^{14}$ Pero no hay información que sostenga que estamos todos comprometidos en el cumplimiento de la recomendación.

No podemos soslayar el impacto de la pobreza sobre el problema que abordamos y es trascendente conocer las condiciones de accesibilidad al sistema de salud e indicadores de seguridad alimentaria de las poblaciones que estudiamos.

El estudio de Zapata et al. tiene la riqueza de enfocar el tema desde la perspectiva del ciclo de vida. Por tratarse de una encuesta cerrada no aparece la leche materna como fuente de hierro de menores de dos años. Pero sí la fuente de hierro de las embarazadas y las madres en periodo de lactancia. Si bien el hierro de la leche materna se mantiene estable en diferentes estados nutricionales, intervenciones con suplementación con hierro demostraron el aumento significativo del hierro en la leche materna. ${ }^{15}$

Conceptualmente la OMS considera que las madres y los lactantes forman una unidad biológica y social; comparten problemas de malnutrición y salud-enfermedad. ${ }^{16}$

Antes de la concepción, la salud y el estado nutricional de la madre tienen una profunda influencia en el desarrollo fetal y el desarrollo de la glándula mamaria.

Las reservas nutricionales de la mujer lactante pueden estar más o menos agotadas como resultado del embarazo y la pérdida de sangre durante el parto.

La lactancia plantea necesidades nutricionales especiales, fundamentalmente por el drenaje de nutrientes a través de la leche materna. ${ }^{17}$
El ciclo de vida es un abordaje que permite entender las vulnerabilidades y oportunidades de intervenir durante etapas tempranas del desarrollo; muestra que las experiencias transcurren a lo largo de la vida, que el impacto de las intervenciones en una generación repercutirá en las siguientes, y que el mayor beneficio deriva de intervenciones previas.

Por otro lado, optimiza el uso de recursos escasos, facilitando la identificación de riesgos y brechas y la priorización de intervenciones.

El trabajo de Zapata et al., quizás sin proponérselo, es una llamada para abrir el debate de un tema siempre prevalente. Propone el conocimiento de las fuentes alimentarias, y además, nos acerca no ya al nutriente aislado para estudiar la deficiencia del mismo, sino al concepto de alimentos y patrón alimentario propuesto por autores fundamentales. ${ }^{18}$

Se ha producido información científica importante en nuestro medio sobre un tema complejo, como la anemia nutricional, que se transmite en nuestra población de generación en generación como una herencia injusta. Algo nos pasa que no podemos transformar el conocimiento en intervenciones efectivas.

\section{Dr. Horacio F. González}

Instituto de Desarrollo e Investigaciones Pediátricas (IDIP) "Prof. Dr. Fernando Viteri" del Hospital de Niños de La Plata (Min Sal/CIC-PBA)

http: / / dx.doi.org/10.5546/ aap.2020.156

Texto completo en inglés:

http: / / dx.doi.org/10.5546/ aap.2020.eng.156

Cómo citar: González HF. Deficiencia de hierro, la injusta herencia. Arch Argent Pediatr 2020;118(3):156-158.

\section{REFERENCIAS}

1. Buchanan GR. The tragedy of iron deficiency during infancy and early childhood. J Pediatr. 1999; 135(4):413-5.

2. Argentina. Ministerio de Salud. Encuesta Nacional de Nutrición y Salud. Documento de resultados 2007. [Acceso: 21 de febrero de 2020]. Disponible en http: / / www.msal. gob.ar/images / stories / bes / graficos / 0000000257 cnt-a08ennys-documento-de-resultados-2007.pdf

3. Varea A, Malpeli A, Disalvo L, Apezteguía M, et al. Evaluation of the impact of a food program on the micronutrient nutritional status of Argentinean lactating mothers. Biol Trace Elem Res. 2012; 150(1-3):103-8.

4. Zapata ME, Rovirosa A, Carmuega E. Hierro y ácido fólico: Natural, enriquecido, fortificado y suplementos. Análisis de las fuentes alimentarias en la ciudad de Buenos Aires. Arch Argent Pediatr. 2020; 118(3):160-5.

5. Calvo EB, Galindo AC, Aspres NB. Iron status in exclusively breast-fed infants. Pediatrics. 1992; 90(3):375-9.

6. Calvo EB, Gnazzo N. Prevalence of iron deficiency in 
children aged 9-24 mo from a large urban area of Argentina. Am J Clin Nutr. 1990; 52(3):534-40.

7. O’Donnell A M, Carmuega E, Durán P. Preventing Iron Deficiency in Infants and Preschool Children in Argentina. Nutr Rev. 1997; 55(6):189-94.

8. Morasso M del C, Molero J, Vinocur P, Acosta L, et al. Deficiencias de hierro y de vitamina A y prevalencia de anemia en niños y niñas de 6 a 24 meses de edad en Chaco, Argentina. Arch Latinoam Nutr. 2003; 53(1):21-7.

9. Morasso M del C, Molero J, Vinocur P, Acosta L, et al. Deficiencia de hierro y anemia en mujeres embarazadas en Chaco, Argentina. Arch Latinoam Nutr. 2002; 52(4): 336-43.

10. Varea A, Malpeli A, Etchegoyen G, Vojkovic M, et al. Short-term evaluation of the impact of a food program on the micronutrient nutritional status of Argentinean children under the age of six. Biol Trace Elem Res. 2011; 143(3):1337-48.

11. Malpeli A, Ferrari MG, Varea A, Falivene M, et al. Shortterm evaluation of the impact of a fortified food aid program on the micronutrient nutritional status of Argentinian pregnant women. Biol Trace Elem Res. 2013; 155(2):176-83.

12. Calvo E, Biglieri A. Impacto de la fortificación con ácido fólico sobre el estado nutricional en mujeres y la prevalencia de defectos del tubo neural. Arch Argent Pediatr. 2008; 106(6):492-8.

13. Bernztein R, Drake I. Subprescripción de hierro y variabilidad en el primer nivel de atención público de la Argentina. Arch Argent Pediatr. 2008; 106(4):320-7.

14. Ceriani Cernadas JM, Carroli G, Pellegrini L, Ferreira M, et al. Efecto del clampeo demorado del cordón umbilical en la ferritina sérica a los seis meses de vida: Estudio clínico controlado aleatorizado Arch Argent Pediatr. 2010; 108(3):201-8.

15. Marin GH, Mestorino N, Errecalde J, Huber B, et al. Personalised iron supply for prophylaxis and treatment of pregnant women as a way to ensure normal iron levels in their breast milk. J Med Life. 2012; 5(1):29-32.

16. WHO, UNICEF. Global Strategy on infant and young child feeding. 2012. [Acceso: 21 de febrero de 2020]. Disponible en: https: / / www.who.int/nutrition/ publications / infantfeeding/9241562218/en/

17. Neville MC, Anderson SM, McManaman JL, Badger $\mathrm{TM}$, et al. Lactation and neonatal nutrition: defining the critical questions. J Mammary Gland Biol Neoplasia. 2012; 17(2):167-88.

18. Mozaffarian D, Rosenberg I, Uauy R. History of modern nutrition science-implications for current research, dietary guidelines, and food policy. BMJ. 2018; 361:k2392.

\section{Estudio clínico-epidemiológico de las infecciones respiratorias agudas bajas causadas por adenovirus en niños hospitalizados. Diecinueve años de vigilancia epidemiológica activa [Comentario]} Clinical and epidemiological study of acute lower respiratory tract infections caused by adenovirus in hospitalized children. Nineteen years of active epidemiological surveillance [Commentary]

Las infecciones respiratorias agudas son la principal causa de morbilidad en la población pediátrica. Si bien en las áreas de bajos recursos la carga de enfermedad es mayor, en las áreas de mayores recursos los desafíos son la resistencia a los antibióticos en las infecciones bacterianas y la identificación de nuevos patógenos. ${ }^{1,2}$

En los últimos años se fue generando un creciente desarrollo en la identificación de virus respiratorios y el rol que presentan en las neumonías de la población pediátrica. Con las técnicas moleculares de diagnóstico virológico se informa la detección de hasta un $92 \%$ de virus respiratorios en niños con neumonía. Los virus asociados a neumonía de la comunidad son el adenovirus humano (AdVH), bocavirus humano $(\mathrm{BoVH})$, coronavirus humano $(\mathrm{CoVH})$, enterovirus (EV), virus de la gripe (Flu), metapneumovirus (hMPV), virus parainfluenza (VPI) y virus sincicial respiratorio (VSR). ${ }^{3,4}$
En el estudio de casos y controles realizado por Rhedin y col. en Estocolmo en el que analizaron la asociación de virus respiratorios y neumonía en menores de 5 años, se detectaron virus en 98/121 (81\%) niños con neumonía y 134/ 240 (56 \%) de los controles. En el análisis univariado los virus asociados significativamente con neumonía de la comunidad fueron hMPV $(p<0,001)$, VSR $(p<0,001)$, Flu $(p=0,03)$ y $\operatorname{AdVH}(p=0,05)$, mientras que en el análisis multivariado AdVH no se asoció significativamente con neumonía y se detectó con bastante frecuencia en los controles. ${ }^{3}$ Esto podría relacionarse a que, si bien se sabe que el adenovirus es un patógeno que causa neumonía de la comunidad, se ha observado que puede persistir en el tejido linfático amigdalino durante semanas. Por otra parte también se ha descrito la latencia del adenovirus en los pulmones y la reactivación en el huésped inmunosuprimido. ${ }^{5}$ 